\title{
Urbanidades e ruralidades no semiárido da Bahia: o olhar de um grupo de pesquisa da UNEB
}

\author{
Celso Antonio Favero ${ }^{1}$
}

\section{Resumo}

Propõe-se, neste trabalho, dialogar sobre a produção científica do grupo de pesquisas "territórios, hegemonias, periferias e ausências", da Universidade do Estado da Bahia (UNEB). O rural do Semiárido da Bahia, o campo e o camponês dessa região, são o sujeito e o chão das pesquisas do grupo. Olhando para este chão, com ele e através dele, olha-se para a cidade, o urbano e as "urbanidades" dos urbanos. Nessas pesquisas e através delas tenta-se conhecer o lugar dos rurais camponeses do semiárido nordestino num universo social onde o urbano se impõe, esconde e apaga a não cidade, produzindo uma situação de fronteira. Após a apresentação do contexto e da prática de pesquisa, esboça-se, neste trabalho, a definição dos conceitos que estruturam o pensamento e a prática do grupo, com a finalidade de evidenciar algumas das nuances que formam, inclusive, o olhar para a cidade e sobre a cidade, o urbano e a urbanidade; olhar que se traduz, hoje, no Brasil, na percepção de um enorme déficit de urbanidade na relação do urbano com o rural. Ressalta-se, nessa perspectiva, a forte contradição que permeia a relação entre o urbano e a urbanidade e que transforma o rural camponês dessa região em não lugar, em insignificante, desmanchando-o e retirando-o do mundo dos sentidos.

Palavras-chave: Urbanidade, Território, Situação de Fronteira, Campesinato

\section{Urbanities and ruralities in bahia's semi-arid: The perspective of a uneb's research group}

\begin{abstract}
It is proposed in this paper to discuss about the scientific production of the research group "territórios, hegemonias, periferias e ausências" of the Universidade do Estado da Bahia (UNEB). The rural of Bahia's semi-arid, the countryside and the peasant of this region are the subject and the field of the group's research. Looking at this field, with it and through it, we look at the city, the urban and the "urbanities" of the urban population. On those researches and by them we try to know the place of the peasant rural population of the northeastern semiarid in a social universe where the urban imposes itself, hides and erases the non-city, creating a border situation. After the presentation of the context and research practice, it is outlined in this paper the definition of the concepts that structure the theory and practice of the group, in order to highlight some of the nuances that elaborate, also, the conception of the city and about the city, the urban and the urbanity; conception that translates today in Brazil in the perception of a huge deficit of urbanity in the urban's relationship with the rural. It is noteworthy, in this perspective, the strong contradiction that permeates the relationship between the urban and the urbanity and that transforms the peasant rural population of
\end{abstract}

\footnotetext{
1 Doutorado (PhD) em Sociología pela Université du Québec à Montréal (UQAM), Professor na Universidade do Estado da Bahia (UNEB) e membro do "Grupo de Estudos e Pesquisa Territórios, Hegemonias, Periferias e Ausências". celsoafavero@cnpq.pq.gov.br; celsoafavero@terra.com.br.
} 
Revista ComSertões

this region in non-place, insignificant, undoing them and removing them from the world of sense.

Keywords: Rurality, Urbanity, Border Situation, Peasantry

\title{
INTRODUÇÃO
}

\begin{abstract}
"A cidade é uma mediação entre uma ordem próxima e uma ordem distante. A ordem próxima é aquela do campo circundante que a cidade domina, organiza, explora extorquindo-lhe sobretrabalho. A ordem distante é a da sociedade no seu conjunto (escravista, feudal, capitalista etc.). Enquanto mediação, a cidade também é o local onde as contradições da sociedade considerada se manifestam, como, por exemplo, aquelas entre o poder político e os diferentes grupos sobre os quais esse poder se estabelece" (Lefebvre, 2008, p. 82).
\end{abstract}

O “Grupo de Estudo e Pesquisas Territórios, Hegemonias, Periferias e Ausências” não tem explicitado, entre os seus propósitos e nas suas publicações, o estudo da cidade, do urbano e da urbanidade, a não ser tangencialmente ou olhando de viés. Ele tem como objeto principal de suas preocupações o rural, a ruralidade, e, particularmente, o campesinato no Semiárido da Bahia e do Nordeste do Brasil. Este mesmo Semiárido que hoje, novamente, está sendo transformado em espaço de fronteira do capital, não da restauração de fronteiras estabelecidas no passado, como aquela protagonizada pelo latifúndio nas décadas de 1970-1980, na era da "modernização conservadora" da agropecuária; esse novo espaço de fronteira se insere num novo contexto, o do capital financeirizado do neodesenvolvimentismo ${ }^{2}$. O grupo se propõe, nesse contexto, e neste

\footnotetext{
2 "O neodesenvolvimentismo é o desenvolvimentismo da época do capitalismo neoliberal. Convém destacar seis diferenças. O neodesenvolvimentismo (i) apresenta um crescimento econômico que, embora seja muito maior do que aquele verificado na década de 1990, é bem mais modesto que aquele propiciado pelo velho desenvolvimentismo; (ii) confere importância menor ao mercado interno; (iii) atribui importância menor à política de desenvolvimento do parque industrial local; (iv) aceita os constrangimentos da divisão internacional do trabalho, promovendo, em condições históricas novas, uma reativação da função primário-exportadora do capitalismo brasileiro; $(v)$ tem menor capacidade distributiva da renda e ( $v i$ ) o novo desenvolvimentismo é dirigido por uma fração burguesa que perdeu toda veleidade de agir como força anti-imperialista" (Boito JR e Berringer, 2013, P. 32). Outra característica do neodesenvolvimentismo é o neoextrativismo, definido como "uma versão contemporânea do desenvolvimentismo e apresenta (...) o crescimento econômico como forma de superação da desigualdade social - e que, em sua roupagem recente, se identifica com o financiamento de programas sociais. Neste contexto, os setores extrativistas se manteriam como um pilar da "obsessão pelo crescimento" (...). Além disso, o Estado deixaria de ter como função apenas a manutenção de regras que garantissem o funcionamento dos processos produtivos e passaria a ter um papel protagonista nas
} 
ensaio teórico/metodológico, a contribuir para o estudo dos modos camponeses de produzir a vida e os territórios, e, desse modo, para o estudo das estratégias camponesas no confronto com projetos e agentes que produzem essas novas situações de fronteiras, notadamente os governos e o grande capital. A voz do camponês passa, portanto, por uma tradução, pela leitura de um outro que com ele caminha, vertendo-se na voz da ciência. Isso significa reconhecer, inclusive, que as proclamações das ciencias, de todas as ciencias e de todos os cientistas, são sempre traduções de outros; significa, igualmente, reconhecer que essas traduções, todas elas, podem produzir reificações. Nenhuma ciência e nenhum cientista está imune a isso; são outras vozes de outros sujeitos.

Como está enunciado na apresentação no Diretório do CNPq., nos termos mais amplos, o grupo quer ser um lugar e um meio para o aguçamento dos sentidos de pesquisadores e da própria Universidade no reconhecimento de dinâmicas de produção do social "em situações de fronteiras", e, igualmente, para o esclarecimento de estratégias de agentes sociais deslocados para o outro lado dessas fronteiras, como os camponeses, no seu enfrentamento com os produtores dos sistemas normativos e ideológicos, essencialmente o Estado, e com os que os agentes da sua anulação e morte, as grandes empresas que invadem hoje o Semiárido. Ou seja, o Semiárido do Nordeste do Brasil ${ }^{3}$, principalmente o da Bahia, é o nosso chão, tanto o semiárido camponês quanto o das cidades, das pequenas e das grandes vilas, "dos arruados e das vastidões", essas "paragens brancas onde parece não ter ninguém, nem planta e nem bicho", como diz João Cabral de Melo Neto em "Morte e Vida Severina".

Nos últimos 15 anos, o grupo desenvolveu inúmeros projetos de pesquisa na região ${ }^{4}$, com apoio da Universidade e de órgãos de fomento à pesquisa científica, como o CNPq; contou, principalmente, com o apoio valioso de organizações e de famílias camponesas

atividades extrativas" (Santos e Milanez, 2014, p. 6), inclusive, removendo os impedimentos da aplicação das normas ambientais.

${ }^{3}$ O Semiárido do Nordeste é uma região que envolve uma população de mais de 22 milhões de habitantes. Na Bahia, nos 264 municípios da região semiárida, a população é de quase 6.500 .000 habitantes (mais de $48 \%$ da população do estado). Nessa mesma região, de acordo com os dados do Censo do IBGE de 2010, o grau de urbanização é de 43,23\% (rural: 56,77\%), de modo que, com relação à situação de domicílio, contabiliza-se mais de 3.600 .000 habitantes. Desse total, presume-se que em torno de $80 \%$ pode ser considerada população camponesa e em torno de $10 \%$ pode ser enquadrado, hoje, como agricultor familiar (tem acesso ao PRONAF).

${ }^{4}$ Ver, por exemplo: Favero e Santos, 2002; Favero, 2000. p. 23-48. 
dessas regiões. Dessas pesquisas resultou um número considerável de relatórios e de publicações, e, principalmente, o envolvimento de pesquisadores e estudantes da Universidade com a causa camponesa. Neste momento, estamos desenvolvendo um projeto de pesquisa, com apoio financeiro do $\mathrm{CNPq}$, e com a participação de dezessete bolsistas, dezesseis deles estudantes de graduação da UNEB. Todos os que se envolvem em projetos do grupo - docentes e estudantes - participam de pesquisas de campo, que envolvem a convivência com famílias e com comunidades camponesas. Ou seja, para além dos trabalhos publicados, ou com eles, se atribui grande importância à experiência do envolvimento social e afetivo, que pode transformar mentes: a pedagogia investigativa.

Quem é o camponês? Nos trabalhos de pesquisa, metodologicamente, primeiro, se considera o campesinato como agente social, politico e econômico, e não como um beneficiário de políticas públicas e/ou um desprovido de identidade social; isso, sem perder de vista a continuidade descontínua da sua relação com o Estado (agente principal na produção dos aparatos simbólico/normativos e das políticas públicas da desqualificação do campesinato) e com agentes econômicos (que materializam a concentração do capital e o destruição criativa de agentes "desnecessários"). $\mathrm{O}$ camponês é um agente social, político e econômico, que produz posições, lugares e territórios num contexto complexo que envolve outros agentes, lugares e territórios, escalas e contradições.

Qual é esse "lugar dos rurais camponeses", como eles se auto-identificam, onde vivem e como produzem os seus lugares e as suas vidas? O que é o mundo rural camponês como "espaço de vida" e como espaço de produção de mundo? Como ele se relaciona com o urbano e com a cidade? Seguindo pelas trilhas abertas por inúmeros estudiosos, particularmente Maria Nazareth Baudel Wanderley (2009), estas são algumas das questões que estruturam as nossas buscas e as nossas vivências em pesquisa ao longo desses anos. São questões que induzem outras, que levam a encontros e desencontros com grupos sociais, a conversas e a rodas de conversas. Questões com lugares.

Nessas buscas e vivências pratica-se, em termos metodológicos, uma "pedagogia de troca de saberes" - ela seria, segundo o antropólogo Carlos Rodrigues Brandão, a primeira virtude necessária para o pesquisador do social -; ou, nos termos propostos por José de Souza Martins, cultivamos uma "pedagogia investigativa", de modo que o 
pesquisador torna-se, frequentemente, um inquerido, dando origem a um processo de educação: um aprende com o outro. A pesquisa envolve intrinsecamente, na sua origem, uma dimensão pedagógica.

Nas idas para estes lugares na Bahia, o camponês e nós pesquisadores, moradores da cidade, somos, ambos, parceiros de conversas. Fazemos rodas de conversas, algumas com menos gente, outras mais largas, umas em salas e em fundos de casas, até nas cozinhas, outras em cantos de ruas, em escolas, em bancos de igrejas, envolvendo famílias, pais, filhos e avós, comunidades inteiras, arruados, vilas e até representações de municípios e regiões. Adentramos nesses caminhares pelos sertões andando pelas trilhas provocadoras deixadas por Wright Mills (1980), que deslocam a ciência do social do campo das certezas, da aritmética, para o do "artesanato intelectual"; e, como diz José de Souza Martins, para o campo da aventura. Docentes pesquisadores e alunos de iniciação científica são enredados por essas trilhas nas caatingas ressequidas e/ou florescidas do sertão. Vivemos nesses lugares tempos densos e tempos relativamente largos, assimilados por momentos que escorrem lentos, "modorrentos", e que se aceleram aqui e acolá. Não são lugares parados.

Desses lugares, enfim, também miramos a cidade, o urbano e a urbanidade dos urbanos, distante ou próxima, assimilada nos gestos dos camponeses, na feitura das casas, no artesanato da vida, nas falas e nos silêncios, tantos lugares e modos de desencontros de mundos. Ao mesmo tempo em que nos embebemos da roça, do rural e do modo camponês de relacionamento, nós outros somos mais urbanos, somos a universidade e a cidade. Contradição escancarada, adentrada nos corpos e nas mentes; contradição que, mediada por grandes empreendimentos que reocupam atualmente a região e a transformam em nova fronteira do capital. A fronteira contradição: de lá e de cá, negação mais que contradição, humano e não humano. Nós e...

\section{UM QUADRO CONCEITUAL BÁSICO}

"Essa concepção (revelador-analisador) se refere a situações particularmente significativas para a compreensão da realidade social. As transgressões são analisadoras-reveladoras, pois promovem rupturas que desencadeiam interpretações, reações, transformações reveladoras do que é que está sendo rompido. As ocultações, 
próprias sobretudo da sociedade capitalista, ficam expostas e permitem, assim, a compreensão integral da realidade social" (Martins, 2013, p. 221-222).

É evidente que a ida para o campo, o campo do camponês, é, quando aberta às conversas, portadora de transgressões, aventura. Conceitos, noções, ideias feitas se rompem. Ela rompe com o eu/nós formatado. Não há, nesse caso, um colocar "entre parêntesis" do eu/nós, no sentido da provisoriedade, para a escuta do outro. Há o escancarar de contradições, as mútuas provocação, a desinstalação do eu fixado nos corpos para a abertura à alteridade que constitui o mundo complexo. $\mathrm{O}$ "só sei que nada sei" socrático não é o vazio, é um problema, é abertura para o diverso do eu com o eu que se revela diverso. A preparação para a convivência com o alter - o ato requer preparação - precede a ida para o campo do camponês do Semiárido; para o encontro com o rural do camponês e do não camponês; e para o encontro com o urbano do camponês e do não camponês destilado do próprio camponês.

Pensar o urbano a partir do conceito de urbanidade, pelo menos no Brasil, hoje, nos remete ao mundo dos "desejos" (Hegel, 1992), o "fogo escondido" de Adauto Novaes (1990). A urbanidade torna-se um vir-a-ser. Nos dicionários e no próprio universo do normativo, tende-se a definir a urbanidade como o "amadurecimento" de relações políticas e socioculturais no espaço urbano (como o processo de produção de cidadania), o que facilitaria e orientaria, do ponto de vista dos sujeitos, os seus contatos com o desconhecido, o diferente e o inesperado - inclusive com o que não teria ainda amadurecido, a exemplo do camponês -, que caracterizam a vida social em contextos metropolitanos e submetropolitanos. Visão linear, evolucionista: como o urbano é "maduro" e, portanto, mais evoluído que o rural, a "urbanidade" torna-se a expressão do bom relacionamento, a relação ideal; ela é colonizadora.

A urbanidade envolve, portanto, adequações sociais regidas por códigos comportamentais que garantem o indispensável compartilhamento das condições objetivas de vida em determinados espaços. O contrário da urbanidade, ou, mais precisamente, o seu déficit, já que expressa a qualidade (quantificada) do evoluído, se manifestaria como um ambiente regido pela violência, a competição, o medo, o menos humano; manifesta-se, igualmente, como o não compartilhamento da urbe, a sua apropriação privada (por alguns privados) e a sua não aceitação como obra coletiva, 
como sugere Lefebvre (2008), o que daria origem, freqüentemente, a uma contradição entre a urbanidade e o urbano e à produção de "situações de fronteira", onde a urbanidade é a manifestação da sua própria contraface.

Nos estudos feitos pelo grupo de pesquisas "Territórios, Hegemonias, Periferias e Ausências", o termo "situação de fronteira" - caracterizada como o lugar onde se vive num "abismo histórico" -, um segundo conceito central nos seus olhares para o campo camponês (além de urbanidade), tornou-se, freqüentemente, uma quase obsessão. Não a "obsessão" de Michel Foucher (2009), mesmo considerando que a concepção de fronteira que ele desenvolve é muito importante para o entendimento do fenômeno em determinadas perspectivas, como a dos indispensáveis marcadores de identidade, autoconsciência e diversidade. Estamos mais próximos, nesse caso, provavelmente, de "A Travessia das Fronteiras", de Vernant (2009), ou das fronteiras do tempo, do tempo da escritura e do tempo da memória, de um passado distante agora escriturado, da objetividade distante do intelectual e do seu engajamento apaixonado, hoje, enquanto militante, do familiar e do insólito. O embrenhar-se na fronteira é um ato de aventura, do conflito prenhe, mas, também, do aniquilamento da alteridade e do próprio sentido do humano. Em que o olhar do Semiárido do camponês pelo urbano coincide ou difere do olhar do Semiárido do camponês pelo camponês, quando se afirma que esses lugares (do Semiárido) vivem hoje uma "situação de fronteira"? O de cá e o de lá da fronteira, o existente e o invisível, invisível porque delá...; lugar de confronto e de negação, ao mesmo tempo, lugar da vida e da morte. O que torna o ato de pesquisar, sociológico e antropológico, um ato de aventura, de artesanato intelectual.

Nos nossos estudos, a fronteira se configura como lugar de desencontro e de "confronto", opondo os de lá aos de cá, mais do que como lugar de encontro e de formação de identidades (das alteridades): "longe de ser o território do novo e da

\footnotetext{
${ }^{5}$ De acordo com McAdam, Tarrow e Tilly (2009), o conceito de "confronto político" é matricial no estudo dos movimentos sociais. De acordo com os autores, "um movimento social é uma interação sustentada entre pessoas poderosas e outras que não têm poder: um desafio contínuo aos detentores de poder em nome da população cujos interlocutores afirmam estar ela sendo injustamente prejudicada ou ameaçada por isso. Precisamente porque o confronto político constitui um terreno analítico contínuo com nada mais do que fronteiras fluidas, qualquer definição de movimento social provocará objeções imediatas de estudiosos de áreas adjacentes que se concentram nas suas semelhanças; esta definição específica exclui as reivindicações coletivas de poderosos em relação a poderosos, esforços coletivos para se evadir ou se autorrenovar e alguns outros fenômenos próximos que, de fato, compartilham características importantes com as interações que estão dentro das fronteiras.
} 
inovação", ele se revela diuturnamente, para nós, por um lado, como o "território da morte e o lugar do renascimento e maquiagem dos arcaísmos mais desumanizados, cujas consequências não se limitam a seus protagonistas mais imediatos. Ela se estende à sociedade inteira, em seus efeitos conservadores e bloqueadores de mudanças sociais em favor da humanização e da libertação do homem de suas carências mais dramáticas" (Martins, 2009, p. 13-14). Ela é, nesse sentido, o contrário do que se proclama no imaginário do poder dominante, urbano: no desencontro/confronto que ali se estabelece, realiza-se, mais do que a disputa pela terra e pela água; disputa-se significados e o próprio sentido do viver, que tornam o camponês e o seu universo um insignificante. Em nome do que seria "verdadeiramente" significante, "maduro", "moderno", induz-se um processo de "destruição criativa" (Harvey, 2007), apagando lugares e vidas em nome da sua insignificância e do significado do que seria o novo, o "desenvolvimento", o des-envolvimento, a aniquilação do campo, cujo portador é a cidade ${ }^{6}$.

O espaço da fronteira é, no extremo, o lugar da disputa e, ao mesmo tempo, da ruptura entre a morte e vida, como diz João Cabral de Melo Neto. Nela, o de lá e o de cá se desencontram para se reencontrarem no caminhar longo do largo campo de batalha, no caminho que passa por vastidões onde parece não haver ninguém, "nem bicho e nem árvores", que, se as houve, já não as há; passa por pequenas e quase invisíveis estações, e por estações maiores, já visíveis, os arruados e as cidades.

Esse lugar do desencontro/encontro da morte vida quando olhado de fora, do confronto de dois, se olhado de dentro no que é invisível quando mirado de fora, freqüentemente, nos surpreende pela pujança da vida que nele verte. Lá está a comunidade camponesa no verde cinza da caatinga, o lugar onde o humano - outro humano, não o do capital e do poder da cidade - é o essencial. Este é o mundo rural, a comunidade do camponês, espaço de vida e de produção de vida. Sim, verdade, vida "bloqueada" pelo Estado e

\footnotetext{
${ }^{6}$ Numa das comunidades camponesas centenárias que estão sendo apagadas por uma grande empresa de mineração, em 2013, ouvi de uma moradora resistente o seguinte depoimento: "quando eles conseguem expulsar uma família, a primeira coisa que fazem é demolir a casa e destruir tudo o que é sinal de que ali viveu uma família. Eles acabam com tudo, até com o cemitério, apagando tudo que é sinal que ali existiu uma comunidade. Essa é a dor maior, apagam o nosso passado. Aqui foi enterrado o meu umbigo, o umbigo dos meus filhos, aqui foram enterrados meus pais e avós, essa terra tem o meu suor, essa terra é um pouco de cada um de nós. Saindo, não vai mais nem ter o prazer de voltar, rever, tudo foi apagado, o nosso passado está apagado, desapareceu. Só pensando nisso, choro..."
} 
pelo capital, como diz Maria Nazareth Wanderley (2009), mas, apesar de bloqueada, e contra os bloqueios, uma vida pujante, esperançosa.

Enfim, para nós, pesquisadores pesquisados deste lugar, as múltiplas "situações de fronteira" por onde andamos e paramos ao longo desses anos de andanças transformamse em situações de escola. Situações de fronteiras, situações de escola. Escola aventura, artesanato do sertão. Aprendemos, nesses lugares, que o viver a vida, os modos de produzir a vida e os imaginários sobre a vida e a produção da vida e sobre o humano, podem ser muito diversos; e que, por serem diversos, nos remetem a um campo complexo, sem linearidades, continuidades descontínuas que rompem com a aritmética para nos projetar num universo onde a única verdade que resiste é a da nossa incompletude e da nossa insignificância; e a realidade da alteridade.

Um terceiro conceito, com os de urbanidade e situação de fronteira, que nos tem guiado ao longo desses percursos foi o de território. Conceito que se tornou teimoso, apesar de fugidio. Aqui, para revê-lo, pode-se voltar, em certa medida, à "obsessão por fronteiras", de Foucher: identidade, autoconsciência e diversidade. Ou, também, a Vernant, aos tempos/territórios de sentidos. Nesse campo de estudos, por um lado, acompanhamos e interferimos - em alguma medida - nos debates iniciados (retomados) na década de 1990, e que viraram obsessão. Foram visitados, nessa perspectiva, autores que se tornaram clássicos, entre nós, antes de nós, principalmente após a publicação do livro de Haesbaert (2004): autores como Milton Santos e Henri Lefebvre, só para citar os que mais visitamos. Acompanhamos, também, no prosseguimento dos caminhos, a desidratação desse debate e a sua migração para os lados da administração pública, da gestão e do gerencialismo, ou da sua transformação em aparelhos de controle político social, como o é o da instituição dos Territórios de Identidade e de Cidadania, Brasil afora e Bahia adentro. Territórios de governo, de mando, de controle.

Nos nossos trabalhos, para a definição do conceito de território seguimos pelos caminhos abertos por Giddens (2003), que o estrutura com base nas noções de trajeto e “desencaixe". Entende-se: 1) que o ser humano é um ser situado num espaço-tempo (externo) e portador de um espaço-tempo (interno); 2) que esses espaços-tempo têm as suas fronteiras demarcadas pelas "trajetórias" dos indivíduos e dos grupos sociais que os constituem; 3) que internamente, e entre eles, os territórios são espaços-tempo de tensão que, freqüentemente, se transforma em conflito, e, inclusive, em experiências 
artesanais de promoção de deslocamentos; 4) que os territórios são resultados/espaços de poder, inclusive, do poder de grupos que controlam o Estado; 5) que as relações entre os diversos espaços-tempo vividos e os de poder podem dar origem a escalas de territórios e a sistemas de mixagem. Nas palavras de Giddens, nos territórios as fronteiras tendem a "se acomodar sob as pressões e as oportunidades que decorrem de sua existência comum" (Giddens, 2003, p. 143).

Mas é, talvez, no Auto de Natal que se encontra a melhor imagem do território, o território vivido, antes do território de poder, nas palavras de Milton Santos:

“ - Antes de sair de casa

aprendi a ladainha

das vilas que vou passar

na minha longa descida.

Sei que há muitas vilas grandes,

cidades que elas são ditas;

sei que há simples arruados,

sei que há vilas pequeninas,

todas formando um rosário

cujas contas fossem vilas,

todas formando um rosário

de que a estrada fosse a linha"
Vejo agora: não é fácil

seguir essa ladainha;

entre uma conta e outra conta

entre uma e outra ave-maria,

há certas paragens brancas,

de planta e bicho vazias,

vazias até de donos,

e onde o pé se descaminha.

Não desejo emaranhar

o fio de minha linha

nem que se enrede no pelo

hirsuto desta caatinga".

Entre o território vivido (o da casa, onde aprendeu a ladainha das vilas da longa descida), o território caminhado (dos vazios e das paragens brancas, dos arruados) e o território imaginado e desejado (das vilas e das cidades), porque o território vivido está 
se desmanchando, há o caminho a percorrer, o percorrer do rosário pelo "hirsuto da caatinga". O camponês parte e, ao mesmo tempo, torna-se um passante, um sem lugar no território fugidio, torna-se mundo: do corte de cana em São Paulo á construção civil em Salvador ${ }^{7}$. Caminhar, o caminhar do sem chão, faz parte do seu ser, o ser camponês. Apesar de teimoso, de enraizado na comunidade e no chão da caatinga, ele precisa partir; e voltar, por que o lugar o chama. Exceto quando o lugar se desmancha em nome do desenvolvimento da cidade, do apagamento da sua história ${ }^{8}$.

O quarto conceito da nossa indagação é o de camponês. Nos nossos estudos, mais do que perseguir a produção ou a remissão a um conceito substantivo de "camponês", e, inclusive, indagando se é possível fazê-lo, considerando a realidade brasileira e, principalmente, do Semiárido Nordestino, preferimos fixar-nos em uma definição de caráter mais propriamente político/antropológico desse personagem. Identificamos nos nossos caminhares pelo Semiárido a existência de um personagem para o qual não se tem uma designação substantiva que seja, mesmo para nós, minimamente convincente. Quem é esse camponês? Bartra (2011), seguindo na mesma toada, o percebe como "um emaranhado de relações sociais cujos nós são a comunidade, a vida rural, o povoado, o governo local, a associação agrícola, a região...”. De acordo com o autor, ele é um "sobrevivente" nas fronteiras do capital, uma "classe esquiva", "raça errante", cuja imagem (máscara) se esvai nas cordas de uma "vida suspensa"; ele constitui uma raça de marginais, polimorfos perversos, peregrinos dos tempos e dos espaços, excluídos da história e da humanidade, tudo em nome do progresso do capital que subordina o humano. Ele é, igualmente, um personagem social/político do Semiárido nordestino.

Ao contrário dos proclamados agricultores familiares, designação igualmente problemática, mas mais na moda e alçada ao campo da administração pública estatal, politicamente, ele é, aparentemente, um insignificante. O camponês brasileiro, do Semiárido nordestino, não é insignificante! Ele é o produtor de uma cultura que é patrimônio do Semiárido, a cultura camponesa, nas suas muitas expressões: ribeirinha,

\footnotetext{
${ }^{7}$ Uma das notas recorrentes nas rodas de conversas são as ausências: quase todas as casas possuem os seus ausentes; ausentes presentes nas rodas, territórios alargados, mundo sem eira nem beira, esse mundão de meu Deus. Territórios de caminhadas, ele vai e retorna.

${ }^{8}$ Um fenômeno tenebroso e cada vez mais recorrente no Semiárido, vertido no confronto entre comunidades camponesas e grandes empresas mineradoras, de produção de energia eólica e do hidroagropecuárias é o do apagamento de lugares e, assim, do passado de comunidades, para a certeza do não retorno. Lugares sagrados são profanados em nome do crescimento do capital.
} 
sertaneja, quilombola, indígena, de fundo de pasto... Ele é a própria cultura. Mas, principalmente, e simplesmente, ele é humano.

Ele não é insignificante, inclusive, do ponto de vista do capital e do poder, e aí está uma contradição, se o identificarmos enquanto trabalhador para o capital (que aloca a sua força de trabalho na própria região do Semiárido e em distantes regiões do país). Muito freqüentemente, ele é transformado em vítima de trabalho em condições similares às de trabalho escravo, a destituição produtiva de sua humanidade. Ele não é insignificante, ainda, quando o transformamos em capital político, voto que sustenta poderes poderosos: "o capital não proletariza a totalidade da força de trabalho, particularmente na agricultura" (Wanderley, 2009, p. 95), proletarizando o trabalho necessário para o capital. De acordo com a autora,

“a) sob a dominação do modo capitalista de produção, o campesinato ocupa um espaço criado pelo próprio capital, em funcionamento no setor agrícola;

b) este espaço é o de um trabalhador para o capital, distinto do proletariado...;

c) por conseguinte, o campesinato, ao ocupar este espaço, se transforma qualitativamente...;

d) a reprodução do campesinato, nestas condições, depende não necessariamente do grau de desenvolvimento do capitalismo, mas, fundamentalmente, das condições históricas de funcionamento do capital..." (Ibid., p. 96).

Qual é o lugar do camponês no Semiárido Nordestino? Estudos com base nas informações do Censo Agropecuário de 2006 e do Censo Geral de 2010 (Buainain et al., 2013) consideram que, nas últimas décadas, a agropecuária brasileira, induzida pela elevação de preços internacionais de commodities e a ampliação do mercado interno, ingressou em nova fase competitivo/tecnológica reassumindo posição estratégica na produção de resultados da balança comercial e no cenário político nacional. Esses estudiosos consideram, no entanto, que, em termos de regiões e no interior delas, o setor agropecuário continua marcado por elevados níveis de desigualdade social e de pobreza; e que estaria em gestação, hoje, no Brasil, o que eles chamam de um "desenvolvimento bifronte", que combinaria/descombinaria "um lado alvissareiro de crescimento rápido da produção agropecuária, ancorado em taxas elevadas de produtividade" (protagonizado pelo chamado agronegócio), com um lado “socialmente negativo, senão 
perverso, de seletividade social, situação agravada pela incompreensão da ação governamental..." (Navarro e Campos, 2013: p. 18).

Essa "diferenciação social”/“desenvolvimento bifronte” é identificável, segundo Miele e Miranda (2013), considerando três "mudanças" (e a assimetria de sua repercussão nas duas frentes) que estariam em processo na agropecuária brasileira: 1) o contínuo aumento da escala da produção; 2) a crescente especialização dos produtores; 3) a crescente intensificação tecnológica. A desigualdade resultaria, portanto, e essencialmente, da intensificação tecnológica e, conseqüentemente, do aumento da produtividade, onde se combinam/descombinam um continuum geral com ritmos (e regiões) mais ou menos lentos, de modo que, por exemplo, o Semiárido do Nordeste se identificaria, nesse cenário geral, como um vasto espaço rural e, principalmente, como lugar do atraso.

No entanto, com base nos estudos realizados pelo grupo de pesquisa, entende-se, sobre este "lugar do atraso": 1) que se produziu, na longa história, uma representação que o identifica (o lugar do atraso) com a ineficiência, a ineficácia e o desperdício; 2) que o atual processo de implantação/requalificação, na região, de grandes empreendimentos para a produção energética, agropecuária e mineral, e de grandes obras públicas, como a Ferrovia Oeste-Leste FIOL) e a transposição das águas do Rio São Francisco, vêm transformando-a em nova fronteira do capital; 3) que esses processos vêm produzindo entre os camponeses da região uma crescente ruptura separando os $10 \%$ "melhor sucedidos", os chamados agricultores familiares (eles têm acesso ao PRONAF), e os 90\% que, para a sua reprodução, dependem das políticas de Previdência e Assistência Social $^{9}$; 4) que esses processos vêm produzindo, igualmente, na região, a extinção de diferentes expressões ou formas camponesas de produção de vida, incluindo assentamentos rurais, "comunidades tradicionais" e territórios de comunidades

\footnotetext{
${ }^{9}$ Esse vasto grupo da população rural, embora seja identificado em quase todos os estudos e no campo das políticas públicas como de agricultores familiares, rigorosamente, ele nos escapa dessa definição e é melhor qualificado como camponês, nos termos que o definimos acima. Para este personagem, para além do problema da dificuldade ou da exclusão do acesso às tecnologias consideradas modernas, ele enfrenta, ainda, problemas de acesso à terra, à água e a serviços públicos.
} 
Revista ComSertões

identificadas como de "fundos de pasto", de "refrigério", de "fechos", ribeirinhas, sertanejas $^{10}$.

Não se pode perder de vista, no entanto, e essa é a sua expressão da fertilidade, que a região vem se transformando, na sua contramão, no nascedouro de novos sujeitos econômicos, sociais e políticos, de novas conflitualidades e de novas formas de desigualdades, de pobrezas e de exclusões, ao mesmo tempo em que expressões tradicionais destas estariam em processo de requalificação. Estão se refazendo, também, os significados (e os lugares e os tempos nas estruturas) de elementos estruturantes das formas camponesas e familiares de produção, tais como a terra, a água, as tecnologias, os modos de produção e, também, os lugares, as habitações e os costumes (tradições) e, inclusive, os seus sistemas internos de direitos, o que repercutirá na relação entre esses personagens, por exemplo, e o Estado. Essas novas dinâmicas, ao violarem lugares, tempos e sistemas de produção/reprodução de vida baseados em determinadas relações com esses elementos colocam em questão a própria viabilidade ou a reprodução da agricultura camponesa e familiar e, igualmente, dessas comunidades.

\section{CONSIDERAÇÕES FINAIS}

Se, por um lado, a cidade, o urbano e a urbanidade não constituem a temática central do trabalho de investigação do grupo, ela reaparece de forma bastante significativa na medida em que se coloca em evidência, a partir do rural e das ruralidades, as contradições e os confrontos que estruturam as relações entre os camponeses e seus modos de produção de vida, notadamente em situações de fronteiras, com os agentes do

\footnotetext{
${ }^{10}$ Com base em preceito constitucional, em fevereiro de 2007 foi sancionado o Decreto 6.040, que institui a Política Nacional de Desenvolvimento Sustentável dos Povos e Comunidades Tradicionais, que são assim definidos: Art. 3ㅇ, I - "grupos culturalmente diferenciados e que se reconhecem como tais, que possuem formas próprias de organização social, que ocupam e usam territórios e recursos naturais como condição para sua reprodução cultural, social, religiosa, ancestral e econômica, utilizando conhecimentos, inovações e práticas gerados e transmitidos pela tradição". Os Territórios Tradicionais são definidos, na sequencia, como: "Il - os espaços necessários à reprodução cultural, social e econômica dos povos e comunidades tradicionais, sejam eles utilizados de forma permanente ou temporária, observado, no que diz respeito aos povos indígenas e quilombolas, respectivamente, o que dispõem os artigos 231 da Constituição e 68 do Ato das Disposições Constitucionais Transitórias e demais regulamentações".
} 
Revista ComSertões

Estado e do capital, portadores idealizados dos símbolos da urbanidade. O Semiárido do Nordeste do Brasil tornou-se, nas últimas décadas, outra vez e de modos novos, região de fronteira, onde, em nome do desenvolvimento, se disputa, além da terra e da água, territórios e modos de produzir a vida e de viver e o próprio significado do humano. Além de deslocar o campesinato para o âmbito da insignificância e de transformá-lo em vítima da destruição criativa perpetrada pelos agentes do capital, com o aval e a colaboração do Estado, ação que o desmancha enquanto camponês e o põe, fragmentado, nas estradas do mundo, apagando na retaguarda, do seu chão, os sinais que foram da sua existência nos territórios (nas palavras de João Cabral de Melo Neto, no Auto de Natal).

— Esse chão te é bem conhecido

(bebeu teu suor vendido).

— Esse chão te é bem conhecido

(bebeu o moço antigo).

— Esse chão te é bem conhecido

(bebeu tua força de marido).

- Desse chão és bem conhecido

(através de parentes e amigos).

- Desse chão és bem conhecido

(vive com tua mulher, teus filhos).

- Desse chão és bem conhecido

(te espera de recém-nascido).

Esse chão da vida e da gente do Semiárido, em nome do desenvolvimento, torna-se chão do capital. Não da urbanidade. Ele torna-se, também, nas fímbrias dos tempos e dos espaços, tempo de resistência e de vida, vida de gente que teima ser gente.

\section{REFERENCIAS BIBLIOGRÁFICAS}

BARTRA, Armando. Os novos camponeses: leituras a partir do México profundo. São Paulo: Cultura Acadêmica; Cátedra UNESCO de Educação do Campo e Desenvolvimento Rural, 2011.

BOITO JR., Armando and BERRINGER, Tatiana. Brasil: classes sociais, neodesenvolvimentismo e política externa nos governos Lula e Dilma. Rev. Sociologia 
Revista ComSertões

Política [online]. 2013, vol.21, n.47, pp. 31-38. http://www.scielo.br/pdf/rsocp/v21n47/04.pdf

BUAINAIN, Antonio Márcio e GARCIA, Junior Ruiz. Os pequenos produtores rurais mais pobres ainda tem alguma chance como agricultores? In. CENTRO DE GESTÃO E ESTUDOS ESTRATÉGICOS - CGEE. A pequena produção rural e as tendências do desenvolvimento agrário brasileiro: ganhar tempo é possível? Brasília: CGEE, 2013. P. $29-72$

FAVERO, Celso Antonio e SANTOS, Stella Rodrigues dos. Semi-árido: fome, esperança, vida digna. Salvador: EDUNEB, 2002.

FAVERO, Celso Antonio et al. Reduction of Rural Poverty: Critical Revision of the Situation and Challenges for the Next Century. In. Winrock International and Faculdade Integrada da Bahia. Rural Poverty in the Northeast of Brasil. Salvador, Casa da Qualidade Editora Ltda. 2000. P. 23-48.

FOUCHER, Michel. Obsessão por Fronteiras. São Paulo: Ed. Radical, 2009.

GIDDENS, Anthony. A constituição da Sociedade. São Paulo: Martins Fontes, 2003.

GODOI, Emília Pietrafesta; MENEZES, Marilda Aparecida; MARIN, Rosa Acevedo (Org.). Diversidade do campesinato: expressões e categorias, v.2: estratégias de reprodução social. São Paulo: Editora UNESP; Brasília: Núcleo de Estudos Agrários e Desenvolvimento Rural, 2009.

HAESBAERT, Rogério. O Mito da desterritorialização. Do "fim dos territórios" à multiterritorialide. Rio de Janeiro: Bertrand Brasil, 2004.

HARVEY, D. Neoliberalismo como Destruição Criativa. INTERFACEHS - Revista de Gestão Integrada em Saúde do Trabalho e Meio Ambiente 2 (4). Tradução, Agosto de 2007. Disponível em: 〈www.interfacehs.sp.senac.br〉.

HEGEL, Georg Wilhelm Friedrich. Fenomenologia do espírito. Vol. I e II. 2. Ed. Petrópolis: Vozes, 1992.

LEFEBVRE, Henri. Espaço e Politica. Belo Horizonte: Editora da UFG, 2008.

MARTINS, José de Souza. Fronteiras: a degradação do outro nos confins do humano. São Paulo: Hucitec, 2009.

MARTINS, José de Souza. A Sociologia como aventura: Memórias. São Paulo: Contexto, 2013.

MCADAM, Doug, TARROW, Sidney e TILLY, Charles. Para Mapear do Confronto Politico. In. Lua Nova, No.76: São Paulo: 2009. P. 11-48.

MIELE, Marcelo e MIRANDA, Cláudio Rocha de. O desenvolvimento da agroindústria brasileira de carnes e as opções estratégicas dos pequenos produtores de suínos do Oeste Catarinense no início do século 21. In. CENTRO DE GESTÃO E ESTUDOS ESTRATÉGICOS - CGEE. A pequena produção rural e as tendências do desenvolvimento agrário brasileiro: ganhar tempo é possível? Brasília: CGEE, 2013. P. 201-231.

MILANEZ, Bruno e SANTOS, Rodrigo Salles Pereira dos. Neodesenvolvimentismo e neoextrativismo: duas faces da mesma moeda? $37^{\circ}$ Encontro Anual da ANPOCS. 
Revista ComSertões

Acesso em: http://www.ufjf.br/poemas/files/2014/07/Milanez-2013Neodesenvolvimentismo-e-neoextrativismo-duas-faces-da-mesma-moeda.pdf

MILLS, C. Wright. A Imaginação Sociológica. Rio de Janeiro: Zahar, 1980.

NAVARRO, Zander e CAMPOS, Sílvia Kanadani. A "pequena produção rural" no Brasil. In. CENTRO DE GESTÃO E ESTUDOS ESTRATÉGICOS - CGEE. A pequena produção rural e as tendências do desenvolvimento agrário. Brasília: CGEE, 2013. P. 13-28.

NETO, João Cabral de Melo. Morte e vida Severina (Auto de Natal Pernambucano). In. http://www.releituras.com/joaocabral_morte.asp

NOVAES, Adauto (Org.). O Desejo. São Paulo: Companhia das Letras; Rio de Janeiro: Funarte, 1990.

SANTOS, R. S. P.; MILANEZ, B. Neodesenvolvimentismo às avessas? Uma análise do atual modelo de desenvolvimento brasileiro Rio de Janeiro. Texto para Discussão. 2014. Acesso em: http://www.ufjf.br/poemas/files/2014/07/Santos-2014Neodesenvolvimentismo-\%C3\%A0s-avessas.pdf

VERNANT, Jean-Pierre. A Travessia das Fronteiras: entre Mito e Política II. São Paulo: EDUSP, 2009

WANDERLEY, Maria Nazareth Baudel. O Mundo Rural como um Espaço de Vida. Reflexões sobre a Propriedade da Terra, Agricultura Familiar e ruralidade. Porto Alegre: Ed. UFRGS, 2009. 